\title{
Identifikasi Karakteristik Pengelolaan Ekowisata Mangrove Wonorejo Berdasarkan Preferensi Stakeholder
}

\author{
Mega Widiyah Wati dan Hertiari Idajati \\ Departemen Perencanaan Wilayah dan Kota, Fakultas Teknik Sipil dan Perencanaan, Institut Teknologi \\ Sepuluh Nopember (ITS) \\ e-mail: ide_archits@yahoo.com
}

\begin{abstract}
Abstrak-Perubahan kawasan konservasi menjadi kawasan ekowisata ternyata menimbulkan penurunan kualitas lingkungan seperti contohnya kerusakan mangrove, menurunnya hasil tangkapan ikan dan berkurangnya spesies burung peksia. Kerusakan ini disebabkan oleh pengelolaan yang kurang memperhatikan daya dukung lingkungan. Selain itu, pengelolaan ekowisata dianggap belum sepenuhnya melibatkan masyarakat lokal. Pelibatan masyarakat masih bersifat pasif. Untuk itu, tujuan dari penelitian ini adalah untuk mengidentifikasi karakteristik pengelolaan ekowisata mangrove wonorejo berdasarkan prinsip ekowisata. Metode yang digunakan adalah content analysis. Hasil dari penelitian ini menunjukkan bahwa karakteristik pengelolaan ekowisata mangrove wonorejo belum memenuhi prinsip ekowisata khususnya prinsip konservasi lingkungan dan manajemen kelembagaan. Pengelola ekowisata masih terdiri dari 3 pengelola yang tidak terkoordinasi dengan baik sehingga masih adanya konflik antar stakeholder. Karya penelitian ini diharapkan dapat menjadi masukan bagi pengelola sehingga dapat dilakukan peningkatan kualitas pengelolaan agar ekowisata dapat berkelanjutan.
\end{abstract}

Kata Kunci-ekowisata, mangrove, content analysis, pengelolaan berkelanjutan.

\section{PENDAHULUAN}

$\mathrm{E}^{\mathrm{k}}$ KOWISATA mangrove wonorejo adalah salah satu tempat wisata di kota Surabaya yang memiliki potensi keindahan alam dan kekayaan budaya yang bernilai tinggi dalam pasar industri ekowisata. Tujuan dari adanya ekowisata adalah mengembalikan fungsi hutan mangrove, mengurangi pembalakan liar dan melestarikan lingkungannya. [1]

Namun, beberapa fakta menunjukkan bahwa perubahan kawasan konservasi menjadi ekowisata ternyata menimbulkan penurunan kualitas lingkungan seperti contohnya kerusakan mangrove, menurunnya hasil tangkapan ikan dan berkurangnya spesies burung peksia [2]. Menurut hermawan dalam [3], penurunan kualitas lingkungan ekowisata disebabkan oleh pengelolaan yang kurang memperhatikan daya dukung lingkungan. Menurut Hermawan, pihak pengelola ekowisata hanya melakukan penanaman bibit mangrove tanpa adanya upaya untuk perawatan sehingga menyebabkan banyak mangrove yang mati. Selain itu, Singky Soewadji selaku Pengamat dan Pecinta Satwa di Surabaya juga menyebutkan bahwa perusakan mangrove sudah parah di lokasi Kawasan Hutan mangrove, Wonorejo, Rungkut. Bahkan ada beberapa pohon mangrove yang sudah besar tumbang dan akarnya terlihat jelas (beritasurabaya.net, 12 mei 2012). Disamping itu, aktivitas ekowisata juga menyebabkan berkurangnya spesies burung Peksia. [4]

Berdasarkan data pemerhati burung, jumlah spesies yang ada disana mencapai 170 spesies, namun kini tinggal sekitar 70 hingga 80 spesies. Berkurangnya burung ini membuat meningkatnya populasi ulat bulu sehingga mangrove akan meranggas (antaranews.com, 13 mei 2012). Menurut [3], penurunan spesies burung ini disebabkan karena adanya kesalahan pengelola dalam menggunakan perahu untuk aktivitas ekowisata. Hermawan menyebutkan, perahu yang digunakan untuk mengantar wisatawan adalah perahu yang cukup besar dengan warna merah menyala sehingga membuat burung ketakutan dan akhirnya berpindah ke tempat lain . Selain itu, dampak dari aktivitas perahu ini adalah berkurangnya hasil tangkapan udang, tangkapan kepiting, dan ikan. Nelayan yang dulunya memperoleh hasil tangkapan sebanyak $2 \mathrm{~kg}$, kini berkurang menjadi 2 ons sampai 8 ons perhari. Otomatis, penghasilan nelayan akan berkurang [3]. [5]

Hermawan juga menyebutkan bahwa pengelolaan ekowisata belum sepenuhnya melibatkan masyarakat lokal. Pelibatan masyarakat masih bersifat pasif [3] [2].

Melihat beberapa permasalahan pengelolaan diatas, hal ini tidak dapat diabaikan begitu saja karena akan mengancam keberlanjutan dari ekowisata itu sendiri. Untuk itu, perlu adanya pemahaman terkait karakteristik pengelolaan ekowisata agar pengelolaan yang dilakukan sesuai dengan kebutuhan. Dalam penelitian yang berjudul "Identifikasi karakteristik pengelolaan Ekowisata mangrove wonorejo berdasarkan preferensi stakeholder" ini bermaksud untuk mengetahui karkateristik ekowisata dnegan mempertimbangkan preferensi stakeholder diantaranya kelompok pemerintah sebagai pemangku kebijakan yang mengendalikan pemanfaatan ruang; preferensi swasta sebagai pelaku yang mendapatkan manfaat dari adanya ekowisata; preferensi pengelola sebagai eksekutor di lapangan serta preferensi tokoh masyarakat sebagai pengamat sekaligus pemerhati ekowisata. [6]

\section{METODE PENELITIAN}

\section{A. Jenis Penelitian}

Pada penelitian ini, pendekatan yang dilakukan adalah pendekatan penelitian rasionalistik. Jenis penelitian ini adalah penelitian deskriptif kualitatif. 


\section{B. Variabel Penelitian}

Faktor yang akan dibahas dalam penelitian ini terdiri dari 5 faktor yakni konservasi lingkungan, manajemen kelembagaan, edukasi, ekonomi dan peran serta masyarakat. Adapun Variabel yang digunakan dalam penelitian ini meliputi variabel pengelolaan mangrove, penipisan SDA, organisasi pengelolaan, pelibatan stakeholder, anggaran, manajemen wisatawan, promosi, kebijakan/peraturan, fasilitas edukasi, jenis aktivitas edukasi, pelibatan masyarakat lokal, pemberdayaan masyarakat lokal, peluang kerja masyarakat lokal dan peningkatan ekonomi masyarakat lokal.

\section{Metode Pengumpulan Data}

Metode pengumpulan data yang digunakan dalam penelitian ini adalah survei primer dan survei sekunder. Survei primer melalui observasi dan in-dept interview terhadap stakeholder terkait yang terdiri dari kelompok pemerintah (Dinas Pertanian dan Ketahanan Pangan Kota Surabaya, Bapekko Surabaya), kelompok pengelola ekowisata (Koordinator lapangan Mangrove Information Center (MIC), Koordinator lapangan Jogging Track, dan Koordinator lapangan Dermaga), dan kelompok masyarakat (kelompok Tani Mangrove ), serta kelompok sektor privat (PKL Wonorejo). Sedangkan survei primer dilakukan dengan survei instansi untuk memperoleh gambaran umum wilayah penelitian serta survei literatur.

\section{Metode Analisis}

Untuk mengetahui karakteristik pengelolaan ekowisata mangrove wonorejo berdasarkan prinsip ekowisata digunakan metode content analysis yakni sebuah metode penelitian dengan pembahasan mendalam terhadap isi informasi tertulis sehingga dapat ditarik kesimpulan dengan mengidentifikasi berbagai karakteristik khusus suatu pesan secara objektif, sistematis dan generalis. Sedangkan Gubrium et al (1577) dalam [6], content analysis (analisis isi) merupakan suatu metode penelitian yang dilakukan dengan mengkaji dokumen dokumen dengan menfokuskan diri pada penggalian tekstur dan alir pengalaman pengalaman responden melalui interaksi peneliti dan subjek yang ditelitinya dengan teknik wawancara mendalam. Berikut di bawah ini alur content analysis menurut Bungin (2010)

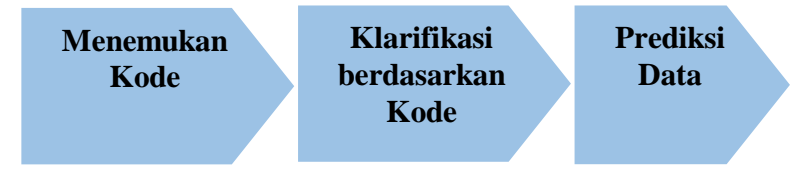

Gambar 1: Alur Content Analysis.

Sumber : Bungin (2010).

Dalam melakukan proses analisis untuk mengidentifikasi karakteristik pengelolaan ekowisata di wilayah studi dilakukan in depth interview dan dianalisis menggunakan content analysis. In depth Interview dilakukan dengan beberapa responden sebagai berikut :

Tabel 1.

Kode Stakeholder dalam penelitian

\begin{tabular}{ccl}
\hline \hline $\begin{array}{c}\text { Huru } \\
\text { f }\end{array}$ & Angka & \multicolumn{1}{c}{ Stakeholders } \\
\hline $\mathrm{G}$ & 1 & Dinas Pertanian Kota Surabaya \\
$\mathrm{G}$ & 2 & Bapekko Surabaya \\
$\mathrm{P}$ & 1 & Pengelola Dermaga \\
\hline \hline
\end{tabular}

\begin{tabular}{cll}
\hline \hline $\mathrm{P}$ & 2 & Pengelola Jogging Track \\
$\mathrm{P}$ & 3 & Pengelola MIC \\
$\mathrm{M}$ & 1 & Kelompok Tani Mangrove \\
$\mathrm{S}$ & 1 & $\mathrm{PKL}$ \\
\hline \hline
\end{tabular}

Maka Dinas Pertanian Kota Surabaya dikodekan G1

Sumber: Penulis, 2017

Tabel 2.

Kode variabel dalam Penelitian

\begin{tabular}{cl}
\hline \hline Angka & $\begin{array}{c}\text { Variabel karakteristik Pengelolaan ekowisata } \\
\text { (Kode: V) }\end{array}$ \\
\hline $\mathbf{1}$ & Organisasi Pengelolaan \\
$\mathbf{2}$ & Pelibatan stakeholder \\
$\mathbf{3}$ & Anggaran \\
$\mathbf{4}$ & Manajemen Wisatawan \\
$\mathbf{5}$ & Promosi \\
$\mathbf{6}$ & Kebijakan/Peraturan \\
$\mathbf{7}$ & Pengelolaan Mangrove \\
$\mathbf{8}$ & Penipisan SDA \\
$\mathbf{9}$ & Fasilitas Edukasi \\
$\mathbf{1 0}$ & Jenis Aktivitas Edukasi \\
$\mathbf{1 1}$ & Pelibatan masyarakat local \\
$\mathbf{1 2}$ & Pemberdayaan masyarakat local \\
$\mathbf{1 3}$ & Peluang kerja masyarakat local \\
$\mathbf{1 4}$ & Peningkatan ekonomi masyarakat \\
\hline \hline
\end{tabular}

\section{Contoh:}

V 13 : menunjukkan penjelasan variabel peluang kerja masyarakat lokal

Berikut adalah contoh proses analisis menggunakan content analisis :

Tabel 3.

Contoh Proses Content Analysis

\begin{tabular}{|c|c|c|c|c|c|}
\hline \multirow{2}{*}{$\begin{array}{c}\text { Karakte } \\
\text { ristik }\end{array}$} & \multirow{2}{*}{$\begin{array}{l}\text { Stake } \\
\text { holder }\end{array}$} & \multicolumn{2}{|c|}{ Indikasi } & \multirow{2}{*}{$\begin{array}{c}\text { Gaya } \\
\text { Bicara }\end{array}$} & \multirow{2}{*}{$\begin{array}{c}\text { Hasil } \\
\text { Analisis }\end{array}$} \\
\hline & & Iya & Tidak & & \\
\hline \multirow{3}{*}{$\begin{array}{l}\text { Anggara } \\
\text { n dana } \\
\text { berasal } \\
\text { dari } \\
\text { pihak } \\
\text { pengelol } \\
\text { a }\end{array}$} & G1 & $\begin{array}{l}\text { V3.1, V3.2, } \\
\text { V3.3, }\end{array}$ & & Datar & \multirow{3}{*}{$\begin{array}{l}\text { Anggaran } \\
\text { dana untuk } \\
\text { pengelolaan } \\
\text { berasal dari } \\
\text { masing } \\
\text { masing } \\
\text { pengelola. }\end{array}$} \\
\hline & G2 & V3.1 & & Datar & \\
\hline & $\mathrm{P} 2$ & $\begin{array}{l}\text { V3.2, V3.3, } \\
\text { V3.5, V3.6, } \\
\text { V3.7, V3.8, } \\
\text { V3.9, } \\
\text { V3.10, } \\
\text { V3.11 }\end{array}$ & & $\begin{array}{c}\text { Ada } \\
\text { Penekanan }\end{array}$ & \\
\hline
\end{tabular}

Sumber: analisis penulis, 2017

\section{HASIL DAN DISKUSI}

Berdasarkan hasil pengkodean menggunakan content analysis berikut adalah karakteristik pengelolaan di kawasan ekowisata mangrove wonorejo :

a. Faktor Manajemen Kelembagaan

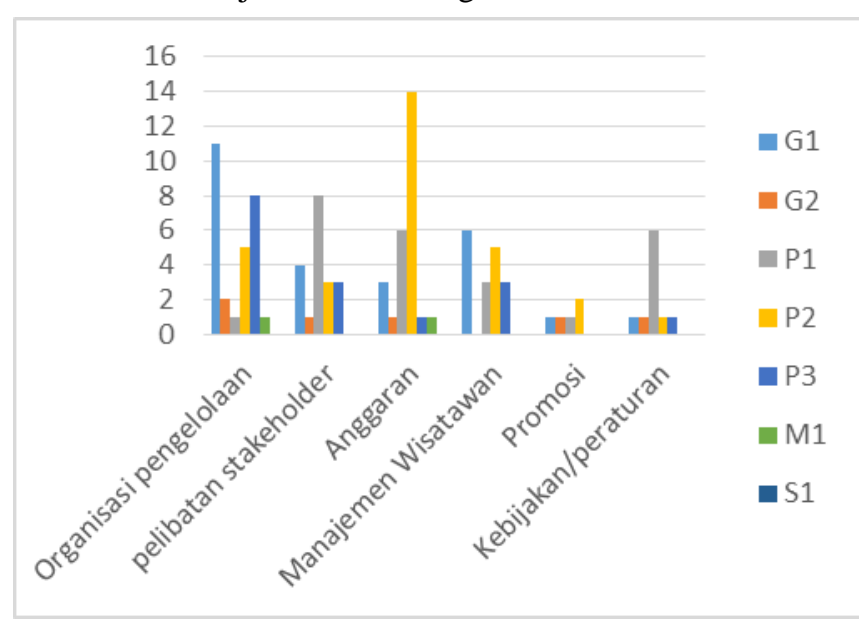

Sumber: analisis penulis, 2017 
Berdasarkan tabel diatas, karakteristik pegelolaan ekowisata mangrove wonorejo dilihat dari faktor manajemen kelembagaan adalah sebagai berikut :

1. Pengelola ekowisata terdiri dari 3 lembaga yang tidak terkoordinasi dengan baik dan tidak memiliki payung hukum yang jelas yakni MIC, LKMK dan FKPM. Kepemilikan lahan ekowisata masih kurang jelas.

2. Pengelola ekowisata mangrove wonorejo terdiri dari pemerintah dan masyarakat. Namun hubungan antara keduanya belum menunjukkan adanya kerjasama dan koordinasi yang baik. Sehingga, pada beberapa stakeholder masih terjadi kesalahpahaman yang menimbulkan tujuan pengelolaan tidak satu visi.

3. Anggaran untuk pengelolaan ekowisata masih berasal dari masing masing pengelola. Anggaran ini berasal dari hasil penjualan ticketing dan dana pribadi dari pengelola serta tidak adanya kontribusi yang masuk ke pemerintah. Namun transparansi anggaran sudah cukup jelas.

4. Ekowisata mangrove wonorejo belum menerapkan pembatasan jumlah pengunjung. Pemerintah sudah mulai merencanakan adanya pembatasan jumlah pengunjung namun belum dilaksanakan. Hal ini dikarenakan kebijakan terkait pembatasan jumlah pengunjung masih dimusyawarahkan dan perlu adanya penelitian terkait hal itu.

5. Promosi ekowisata dilakukan oleh pihak pengelola dengan cara promosi langsung ke sekolah sekolah dengan cara mengundang ke event event tertentu yang telah disiapkan. Promosi juga dilakukan dari mulut ke mulut dan melalui media seperti TV, Koran, website dan sebagainya

6. Peraturan masih mengacu pada Peraturan Wali Kota. Kegiatan perahu ekowisata dan pendirian dermaga belum mendapat izin resmi dari pemerintah kota. Pengelola mengaku izin hanya dilakukan melalui lisan. Sehingga untuk pengelolaan selanjutnya perlu adanya penegakan hukum yang tegas dari pemerintah untuk meminimalisir adanya pihak pihak yang mencari keuntungan dari adanya ekowisata.

b. Faktor Konservasi Lingkungan

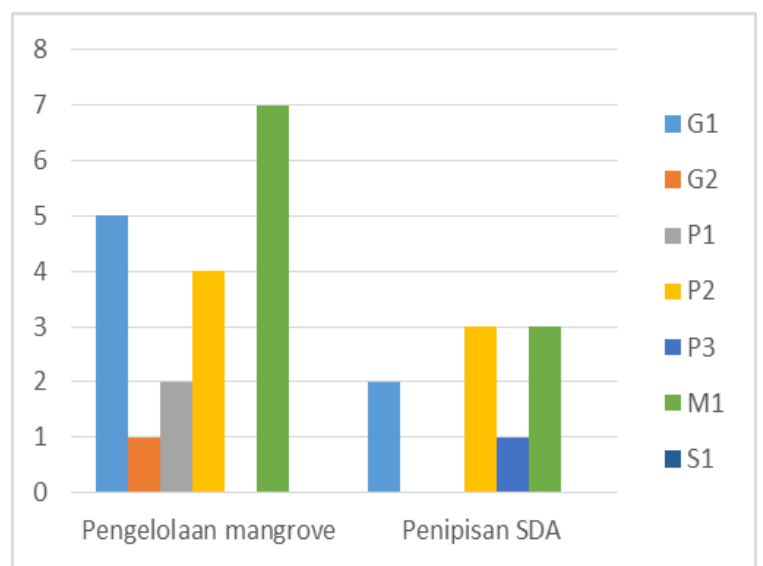

Sumber: analisis penulis, 2017

Dlihat dari faktor konservasi lingkungan. pengelolaan ekowisata mangrove wonorejo belum memenuhi prinsip konservasi. Hal ini ditunjukkan dengan adanya tindakan tindakan pengelola yang belum memperhatikan daya dukung lingkungan seperti contohnya pendirian bangunan di tengah sungai tanpa izin yang resmi dari pemerintah kota Surabaya.
Pengelolaan ekowisata mangrove wonorejo belum memperhatikan prinsip konservasi dan menyebabkan penurunan sumber daya alam yang ada didalamnya. Hal ini dapat ditunjukkan dengan tindakan pengelola yang dengan sengaja mengusir endemis yang ada seperti kera menggunakan senapan dikarenakan menganggu ketenangan pengunjung.

\section{c. Faktor Edukasi}

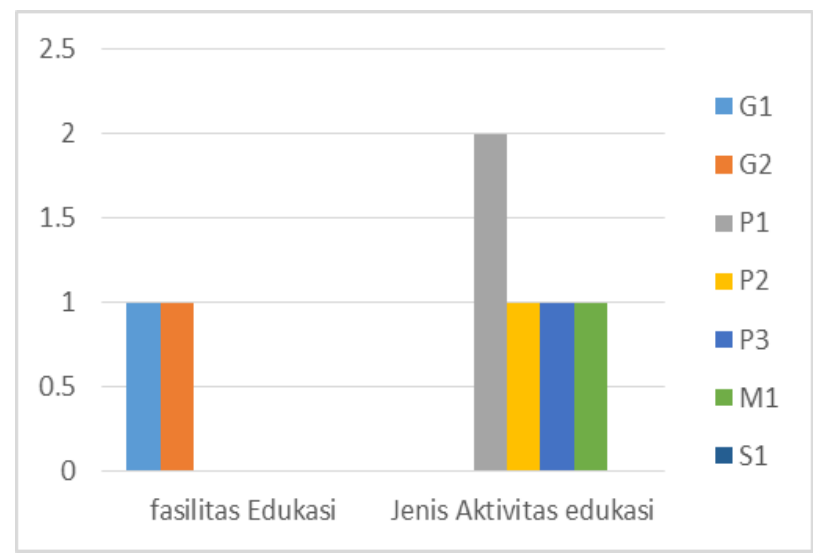

Sumber: analisis penulis, 2017

Berdasarkan hasil dari in-depth interview dengan beberapa stakeholder, fasilitas edukasi yang disediakan oleh pengelola masih berupa papan informasi. Namun papan informasi ini belum komunikatif. Karena wisatawan yang datang lebih banyak mengambil foto daripada membaca papan informasi yang disediakan. Jenis aktivitas edukasi didalam ekowisata berupa pengenalan jenis jenis mangrove kepada siswa yang berkunjung, manfaat mangrove, serta alasan mengapa mangrove harus dilestarikan. Hal ini dimaksudkan agar wisatawan mulai mencintai lingkungan.

\section{d. Faktor Peran Serta Masyarakat}

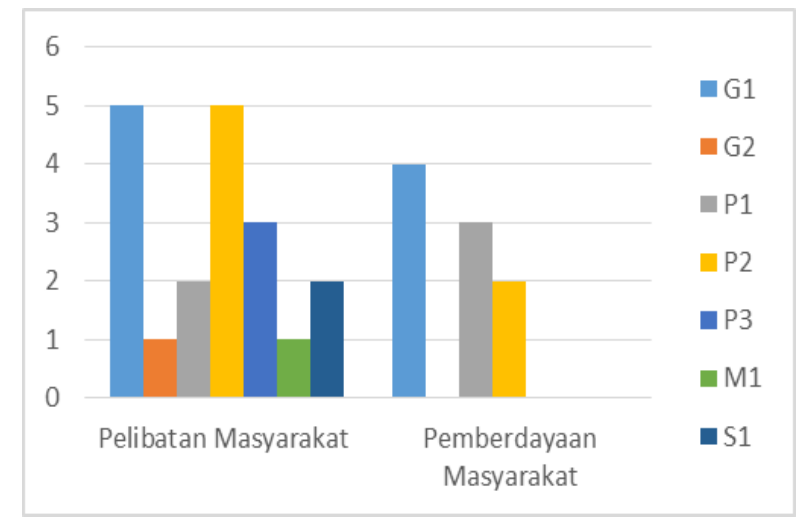

Sumber: analisis penulis, 2017

Dalam proses pengelolaan, pemerintah sudah cukup melibatkan masyarakat dalam pengambilan keputusan suatu program namun pada pelaksanaannya, program tidak sesuai dengan rencana. Hal ini menyimpang dari kesepakatan yang telah disepakati dengan masyarakat seperti contohnya penggusuran PKL warga asli wonorejo. Dalam hal ini, pemerintah sudah melibatkan masyarakat untuk program penggusuran dan menjanjikan akan mendirikan tempat yang lebih layak, namun pada pelaksanannya pemerintah tidak membangun stan PKL sehingga keberadaan PKL jadi tidak tertata. Pemerintah justru mendirikan stan PKL yang dikenal dengan sentra kuliner MIC namun masyarakat yang berjualan sebagian bukan masyarakat wonorejo. 
Ekowisata sudah cukup memberdayakan masyarakat dengan cara merekrut masyarakat lokal sebagai pegawai yang bekerja di ekowisata. Pihak pengelola berkomitmen untuk memberdayakan masyarakat lokal dan keluarga miskin agar taraf ekonominya meningkat. Kapasitas SDM masyarakat masih tergolong rendah. Hal ini dikarenakan sebagian besar pendidikan terakhir masyarakat masih SMA. Sedangkan yang bekerja untuk ekowisata sebagaian ada yang lulusan SD. Kegiatan pemberdayaan yang pernah dilakukan meliputi pelatihan berupa seminar tentang manfaat mangrove, pelatihan pembuatan batik, pembuatan sirup mangrove, dan pengembangan website.

e. Faktor Ekonomi

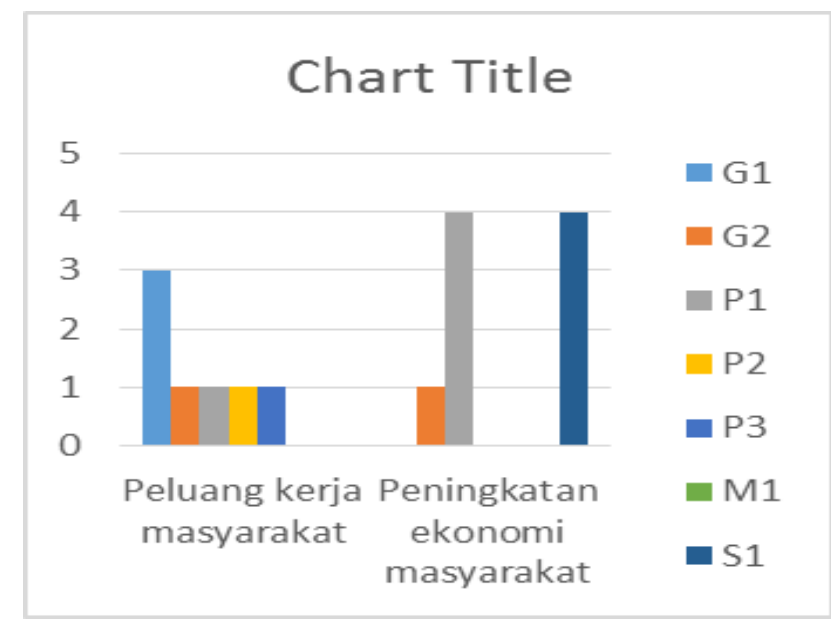

Sumber: analisis penulis, 2017

Pengembangan kawasan konservasi menjadi ekowisata mampu memberikan peluang kerja terhadap masyarakat lokal wonorejo. Masyarakat lokal memiliki peluang kerja untuk berjualan di sentra PKL serta menjadi karyawan yang ikut mengelola ekowisata. Selain memberikan peluang kerja, pengembangan ekowisata juga mampu meningkatkan ekonomi masyarakat. Penghasilan masyarakat terbukti meningkat setelah adanya ekowisata, selain itu, peningkatan ekonomi juga dapat ditunjukkan dengan semakin beragamnya barang yang dijual. Sehingga, pengelolaan ekowisata sudha cukup memenuhi prinsi ekonomi. Namun, pada pelaksanaanya, peningkatan ekonomi berbanding terbalik dengan prinsip konservasi. Sehingga untuk menaikkan ekonomi masyarakt lokal, pihak pengelola kurang memperhatikan aspek lingkungan. '

\section{KESIMPULAN}

Karakteristik pengelolaan yang dilakukan di kawasan ekowisata mangrove wonorejo belum memenuhi prinsip ekowisata khususnya prinsip konservasi lingkungan. Hal ini ditunjukkan dengan adanya tindakan pengelola yang mengusir keberadaan kera karena dianggap menganggu ketenangan pengunjung. Selain itu, pelibatan stakeholder didalam pengelolaan masih kurang baik karena masih adanya konflik antar stakeholder seperti contohnya konflik antara FKPM dan Dinas Pertanian terkait pembangunan dermaga. Sedangkan ditinjau dari partisipasi masyarakat, pengelolaan ekowisata belum sepenuhnya melibatkan masyarakat, namun hanya melibatkan orang orang tertentu saja. Hal ini ditunjukkan dengan adanya ketidakterlibatan masyarakat dalam pembangunan sentra PKL di MIC. Masyarakat yang terlibat sebagian besar adalah masyarakat luar wonorejo. Selain itu, aktivitas edukasi yang ditawarkan juga masih kurang. Hal ini ditunjukkan dengan adanya aktivitas perahu ekowisata yang tidak mengedukasi pengunjung. Sedangkan ditinjau dari aspek ekonomi, pengelola ekowisata sudah cukup memberikan peluang kerja bagi masyarakat lokal dan meningkatkan pendapatan ekonomi.

\section{DAFTAR PUSTAKA}

[1] S. C. Kete, Pengelolaan Ekowisata Berbasis Goa. Yogyakarta: Deepublish, 2016.

[2] V. Rizal, "Pergerakan LSM Nol Sampah dalam mengawal politik hijau kota Surabaya (studi kasus: pendampingan petani lokal pohon mangrove di bosem wonorejo surabaya)," J. Unair, vol. 1, 2012.

[3] A. P. Hertiari Idajati, "The level of participation in Mangrove ecotourism development, Wonorejo Surabaya," Procedia Soc. Behav. Sci., pp. 515-520, 2015.

[4] T. Kiper, "Role of Ecotourism in Sustainable Development," 2013. [Online]. Available: www.intechopen.com

[5] I. Nugroho, Ekowisata dan Pembangunan Berkelanjutan. Malang: Pustaka Pelajar, 2011.

[6] G. R. Somantri, "Memahami Metode Kualitatif," 2005. 